\title{
A fully automatic cardiac model with integrated scar tissue information for improved assessment of viability
}

\author{
Mirja Neizel", Yang Chul Boering, Florian Bönner, Jan Balzer, Malte Kelm, Burkhard Sievers \\ From 15th Annual SCMR Scientific Sessions \\ Orlando, FL, USA. 2-5 February 2012
}

\section{Summary}

This study evaluates whether integration of scar tissue into a patient specific heart model derived from Magnetic Resonance images is feasible.

\section{Background}

Treatment of coronary artery disease can only be effective if myocardial tissue can be identified, that is still viable. To localize scar tissue in relation to the coronary vessels would therefore be desirable for interventional guidance. The aim of this study was to evaluate 1) whether integration of scar tissue into a patient specific heart model derived from Magnetic Resonance (MR) images is feasible and 2) whether this patient specific heart model allows for accurate assessment of the amount of myocardial scar compared to conventional manual infarct sizing.

\section{Methods}

20 patients with clinical indication for viability testing (EF $47 \pm 13 \%$ ) were investigated on a 1.5 Tesla MRI (Achieva, Philips, The Netherlands). Images using a free-breathing 3D-wholeheart balanced TFE sequence triggered to end-diastole were acquired. 10 minutes after injection of a contrast agent $(0.2 \mathrm{ml} / \mathrm{kg} /$ body weight Magnevist ${ }^{\mathbb{R}}$, Bayer, Germany) delayed enhancement (DE) images were acquired using a 3D inversion recovery sequence. Fully automatic segmentation of the heart and great vessels was performed using a comprehensive surface model (Philips Research Laboratories, Aachen, Germany). In addition, information of scar tissue was merged fully automatically from 3D-DE sequence into the segmented whole heart model. Finally, an automatic signal intensity threshold for scar identification was determined. Infarct size and end diastolic left ventricular (ED-LV) volume derived from this model were compared to conventional manual assessment of infarct size and LV volume.

\section{Results}

11 Patients had a chronic occlusion of the right coronary artery (RCA), 3 patients of the left circumflex (LCX) and 6 patients of the left anterior descending artery (LAD).

Integration of viability information into a patient specific heart model was feasible in all cases with identical location of scar tissue compared to DE images.

Infarct size averaged $19 \pm 15 \mathrm{~g}$ by manual tracing and $15 \pm 14 \mathrm{~g}$ by automatic segmentation (Concordance correlation coefficient 0.94 ; limits of agreement $\pm 7 \%$ ). Location of scar tissue was identical between the two analysis methods for all cases.

ED-LV volume was $151 \pm 14 \mathrm{ml}$ by manual assessment and $153 \pm 16 \mathrm{ml}$ by automatic segmentation (Concordance correlation coefficient 0.65 ; limits of agreement $\pm 25 \%$ ).

\section{Conclusions}

A cardiac model with integrated scar tissue information derived fully-automatically from a 3D whole heart MR acquisition as well as a 3D DE-data set is feasible and allows for precise localization and determination of the amount of myocardial scar.

\section{Funding}

No funding. 


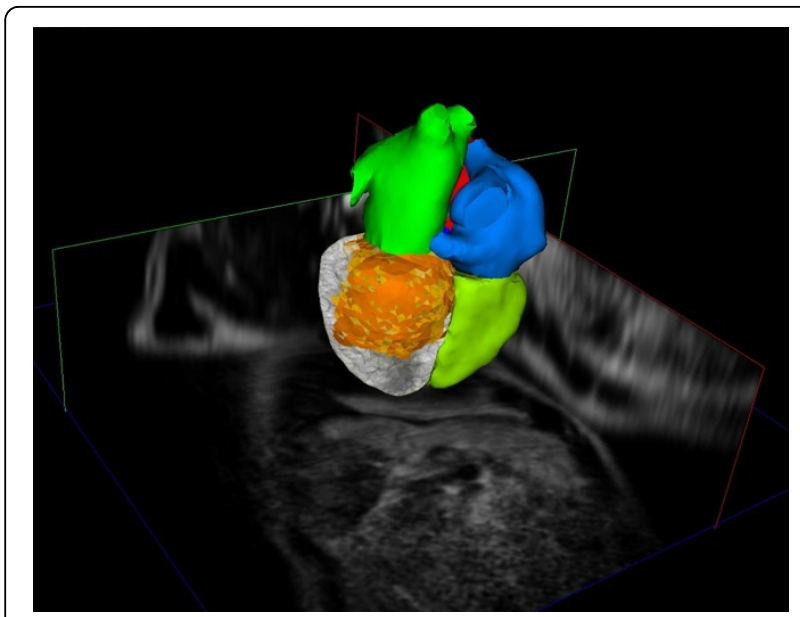

Figure 1 Fully automatic segmentation of a whole heart 3D MR data set. Using the common patient coordinate system an approximate registration of the adapted model with 3D late enhancement data can be achieved. Orange colour indicates scar tissue.

Published: 1 February 2012

doi:10.1186/1532-429X-14-S1-M12

Cite this article as: Neizel et al: A fully automatic cardiac model with

integrated scar tissue information for improved assessment of viability. Journal of Cardiovascular Magnetic Resonance 2012 14(Suppl 1):M12.

Submit your next manuscript to BioMed Central and take full advantage of:

- Convenient online submission

- Thorough peer review

- No space constraints or color figure charges

- Immediate publication on acceptance

- Inclusion in PubMed, CAS, Scopus and Google Scholar

- Research which is freely available for redistribution

Submit your manuscript at www.biomedcentral.com/submit
C Biomed Central 